Int J Adv Manuf Technol

DOI 10.1007/s00170-016-9006-5

CrossMark

ORIGINAL ARTICLE

\title{
Influence of predeformation on microstructure evolution of superplastically formed Al 5083 alloy
}

S. M. Chentouf ${ }^{1} \cdot$ T. Belhadj $^{1} \cdot$ N. Bombardier ${ }^{2} \cdot$ N. Brodusch ${ }^{3} \cdot$ R. Gauvin $^{3} \cdot$ M. Jahazi $^{1}$

Authors' accepted manuscript, article published in

The International Journal of Advanced Manufacturing Technology, vol. 88 issue 9-12, p. 2929-2937 (2016) https://doi.org/10.1007/s00170-016-9006-5

The final publication is available at link.springer.com 


\title{
Influence of predeformation on microstructure evolution of superplastically formed Al 5083 alloy
}

S.M. Chentouf ${ }^{\text {a }}$, T. Belhadj ${ }^{\text {a* }}$, N. Bombardier ${ }^{b}$, N. Brodusch ${ }^{\mathrm{c}}$, R. Gauvin ${ }^{\mathrm{c}}$, M. Jahazi ${ }^{\mathrm{a}}$

a Département de génie mécanique, École de technologie supérieure, 1100, rue NotreDame Ouest, Montréal, QC, H3C 1K3, Canada.

${ }^{\mathrm{b}}$ Verbom Inc., 5066, Route 222 C.P.3240, Valcourt, QC, J0E 2L0, Canada.

${ }^{c}$ McGill University, Wong Building, 3610 University Street, Montréal, QC, H3A 0C5, Canada.

\begin{abstract}
Cavitation is the main defect encountered during Super Plastic Forming (SPF) of thin sheet aluminum alloys. In the present paper, the influence of preforming operation (cold or hot) on super plastic forming ability and quality of $1.6 \mathrm{~mm}$ thick sheet of $5083 \mathrm{SPF}$ aluminum alloy is investigated. Specifically, grain size evolution and the characteristics of the cavitation process are discussed as a function of prior deformation and the preforming temperature. Optical and Field Emission Gun Scanning Electron Microscopy (FEG-SEM) were used to study the characteristics of the cavities and microstructure evolution. Image processing was used to measure the surface and volume fractions of the cavities. The results indicate that hot preforming leads to lower number of cavities per unit surface compared to cold preforming prior to the SPF operation. However, the average cavity sizes and the average grain size are higher in the case of hot preforming compared to cold preforming, which lead to higher susceptibility to crack formation and reduced SPF ability of the alloy.
\end{abstract}

Keywords: Al 5083; Superplastic Forming; Cavity; Grain size.

Authors' accepted manuscript, article published in

The International Journal of Advanced Manufacturing Technology, vol. 88 issue 9-12, p. 2929-2937 (2016) https://doi.org/10.1007/s00170-016-9006-5 


\section{Introduction}

Super Plastic Forming (SPF) process is always conducted at high temperature (usually in the range of 0.5 to 0.75 times the melting temperature) and under low to very low strain rates (generally from $10^{-3}$ to $10^{-5} \mathrm{~s}^{-1}$ ). The sheet material, which must have a fine grain size, is heated to the SPF temperature according to the nature of the alloy and the desired component is formed by applying inert gas pressure between the sheet and the die surface where the sheet material stretches and fills the die cavities. It is well known that SPF process has the advantage of reducing machining times and the number of assembled parts in structural components. Specifically, Zamani et al. reported that by the application of the SPF process to airframe structures, it was possible to reduce the number of parts from 63 to 10 and the number of fixing elements from 1009 to 276 [1]. Moreover, using SPF it is possible to produce complex shapes without the need for welding or riveting operations [2]. While historically SPF has been first used for aerospace alloys such as titanium alloys and high strength aluminum alloys, its application to other alloys is continuously increasing [3].

In recent years, the application of aluminum alloys, mainly as structural components, has significantly increased in transportation industry as it contributes to weight reduction. Specifically, attention is paid to develop fully aluminum structures for electric or hybrid cars. In this context, the application of SPF as an efficient process for forming of thin sheet high strength aluminum alloys becomes very advantageous. Among the various aluminum alloys used in transportation industry, aluminum alloy 5083 is well recognized for its combination of high mechanical properties and formability which makes of it an excellent material for the production of structural components with complex geometries using SPF technology [4].

However, SPF of thin sheets, and specifically that of aluminum alloys, is often associated with the occurrence of cavities in the material during processing. An excessive amount of cavities in the superplastically formed material is undesirable as the growth and coalescence of the cavities may lead to material rupture [5]. Thus, further expansion of the application of the SPF process for forming the new generation of thin sheet aluminum alloys, intended for use as automotive structural components, requires a better understanding of the influence of process parameters on microstructure evolution and 
cavity generation. This knowledge would help optimizing the existing SPF processes or develop new ones which would result in less cavity generation both in terms of its size, morphology, and number.

During the SPF process, parameters such as strain, strain rate, stress, and temperature can differ in different zones of the part [6] and can lead to non-uniform distribution of cavities. These parameters are termed as external factors or extrinsic ones. Those inherent to the material, intrinsic parameters, are grain size [7], second phase particles [8, 9], grain boundary ledges [5,10-12], triple junctions [13-16], micro-voids [13-15], impurities, and grain boundary surface energy [7]. However, while it is accepted that each of the external factors influence the severity of the cavitation process, very little data is available on the combined effects of extrinsic and intrinsic parameters on the severity of the cavitation phenomenon.

Pilling and Ridley [13] as well as Guo and Ridley [17] have carried out extensive theoretical and experimental work on cavitation phenomenon in superplastic aluminum alloys. They have shown that cavity growth is principally controlled by the plastic flow of the matrix rather than diffusion and considered that $50 \%$ of the total strain is due to grain boundary sliding. On this basis, they found that cavitation is lower under plain stain conditions compared to equi-biaxial one. $\mathrm{Wu}$ [18] investigated the influence of deformation parameters under tension deformation conditions and in contrast to the above findings reported that cavitation is lower in equi-biaxially deformed samples compared to uniaxial tension ones. However, a detailed examination of the results reported by $\mathrm{Wu}$ indicates that this observation is only valid for one strain rate condition $\left(2 \times 10^{-4} \mathrm{~s}^{-1}\right)$ and that the difference between the cavity area fractions of plane strain and equi-biaxial conditions is about $10 \%$ for various effective strain levels [18]. In a more recent study, Chan et al. [19], reported that cavitation under uniaxial tension is significantly smaller than under equi-biaxial conditions and that cavitation increased with increasing strain. Chow et al. [20] reported similar results to Chan et al [19], Guo and Ridley [17] and Pilling and Ridley [13] on the influence of strain level on cavitation.

Verma et al. [21] investigated the microstructure of $1.6 \mathrm{~mm}$ thick rolled sheets of 5xxxseries aluminum alloys and showed that non-deformable $\mathrm{Al}_{6} \mathrm{Mn}$ particles $(\sim 0.5 \mu \mathrm{m}$ size $)$ are uniformly dispersed and voids are present at least in every five grains. These non- 
deformable particles were identified as the cause of damage at the matrix/particle interface during cold rolling. It was shown that the damage induced by the particles was not entirely eliminated by the recrystallization process and consequently will become potential nucleation sites for cavities in the post process operations, such as SPF [22]. Nevertheless, Verma et al. [21] also reported that it is possible to control the amount of cavities by increasing the deformation temperature during the SPF process; however, care must be taken for possible abnormal grain growth and cavity coalescence.

In the present paper, the influences of prior deformation conditions (cold or hot preforming) on super plastic forming efficiency of $1.6 \mathrm{~mm}$ thick sheet made of $5083 \mathrm{SPF}$

aluminum alloy are investigated. Special focus is put on the characteristics of the cavities (size, distribution, and morphology) as a function of the amount of thickness reduction. Also, grain size evolution, as one of the critical parameters in the SPF process, is studied as a function of temperature and at specific geometrical locations where the highest deformation is applied to the part. It is worth noting that, to the knowledge of the authors, no prior reports have been published in the literature on the influences of prior deformation temperature (cold or hot preforming) on microstructure evolution and integrity of super plastically formed thin sheet aluminum alloys.

\section{Experimental procedure}

The material used in this study was a 5083 SPF aluminum alloy with H19 temper (cold work, extra hard). The chemical composition of the alloy is provided in Table 1. The investigation comprised: a) the as received material (as reference for comparison purposes), (b) a cold preform; and (c) a hot preform before the SPF process. It must be noted that the geometry of the two preforms were identical in all the experiments.

The cold preform (CP) condition consisted of three steps: a) annealing treatment of the as received material for two hours at $150^{\circ} \mathrm{C}$ followed by air cooling; (b) preforming at room temperature by using a brake press; and finally c) SPF process at $470^{\circ} \mathrm{C}$. The hot preform (HP) condition consisted of two steps: a) preforming of the as received material at $450^{\circ} \mathrm{C}$ during 4 minutes followed by air quenching and b) SPF process at $470^{\circ} \mathrm{C}$. Figure 1 shows the geometry of the preforms and the final shape at the end of the forming process. 
Sample preparation for microstructure examination and cavity characterization consisted of standard polishing until $1200 \mathrm{SiC}$ paper followed by fine polishing up to $1 \mu \mathrm{m}$ diamond suspension and then ultra-fine vibromet polishing using $0.05 \mu \mathrm{m}$ diamond suspension for 24 hours. Cavity observations were accomplished using Olympus DSX500 Opto-digital microscope. For the base material, cavity observations were performed on three directions (i.e. rolling, transverse, and normal). For the CP and HP specimens, observations of the cavities were conducted on the surface as well as at various locations where different thinning levels (named a to $d$ in Table 2) were measured after the SPF process. The surface and volume fractions of the cavities were measured with the aid of metallography image processing (MIP ${ }^{\mathrm{TM}}$ ) [23] on as-polished samples prior to etching. The measurements were made by selecting three zones $\left(2028 \times 2028 \mu \mathrm{m}^{2}\right.$ each) at the surface of the sample (zone 1 center, zone 2 far right, and zone 3 far left) and then averaged.

Microstructure examination and energy dispersive analysis (EDS) were performed by using FEG-SEM Hitachi Su 8230. The "Graf Sergeant Reagent" etchant composed of (15.5 $\mathrm{ml} \mathrm{HNO}_{3}, 0.5 \mathrm{ml} \mathrm{HF}, 3 \mathrm{~g} \mathrm{Cr}_{2} \mathrm{O}_{3}$, and $84 \mathrm{ml} \mathrm{H}_{2} \mathrm{O}$ ) and ion milling was used for revealing microstructural features [24] and the average grain sizes were determined as per ASTM E-112-96 with the aid of metallography image processing (MIP $\left.{ }^{\mathrm{TM}}\right)$.

\section{Results and discussion}

\subsection{Cavitation}

For the as received material, the calculations showed that the percentages of surface occupied by cavities in the normal $(4.16 \%)$ and transverse $(3.57 \%)$ directions are much higher than that for the rolling $(0.05 \%)$ one. These values seem to be consistent with the fact that during the sheet rolling process, because of the pressure hill at the center between the roll and the material and the presence of higher frictional forces, a large number of subsurface discontinuities which are close to the surface are sealed. By contrast, those that are located in the core of the material are less affected. The results also indicate that in the normal and transverse directions, cavities have a multitude of sizes and morphologies. Figure 2 shows cavitation in the normal direction of the rolled 
sheet for the as received. As it can be seen, different forms of cavities are present (circular, rectangular, square, equiaxed). Some of them make junctions that conduct to cracks with a jagged shape. A wide range of cavity sizes is also observed: some of them have a length of around $3 \mu \mathrm{m}$, which can be considered as quite large, while smaller ones of less than $0.5 \mu \mathrm{m}$ are also present. Figure 3 shows a distribution of the length of cavities where the cavity length ranges of $0.47-1 \mu \mathrm{m}$ appear to be the most important one. The larger cavities seem to have been generated from the coalescence of small ones that were localized in the surrounding area during the different steps of rolling.

Figures 4 and 5 show back scattered electron FEG-SEM images of SPF parts for both preforms where precipitates with different compositions and morphologies can be observed. In these images, the contrast level was increased intentionally in order to better display the difference in chemical composition between the different types of precipitates present in the microstructure. As it can be seen, round shape precipitates exist at junctions and within the grains while some smaller ones are localized at the grain boundaries and exhibit a necklace shape. Also, some of them with polygonal shape (rectangular and square) formed by heavy elements, such as manganese, are distributed inside the grains (Figure 6). Figure 6a shows an illustrative example of the morphologies of the abovementioned precipitates. The precipitates were distributed over an area of $90 \mu \mathrm{m}^{2}$. The images are from secondary electron mode obtained at an operating voltage of $5 \mathrm{kV}$ and a working distance of $9.4 \mathrm{~mm}$. In Fig.6b, the backscattered electron signal collected by the large size of the photodiode-backscattered electron (PDBSE) detector at a magnification of $10.0 \mathrm{k}$ is shown, where differences in the chemical composition are clearly revealed by contrast variations. Finally, based on Figure $6 \mathrm{c}$ and as reported in Table 3, characterization of these precipitates indicated that manganese and chromium are the main forming elements. The obtained results are in agreement with those reported by Verma et al. [21] who observed Mn riches precipitates with a composition close to $\mathrm{Al}_{6} \mathrm{Mn}$.

Figures 7 and 8 show the investigated areas of the surface zones of $\mathrm{CP}$ and HP samples, for thinning percentages of 53\% (CP) and 55\% (HP). Examination and comparison of these figures indicate that the dimensions of the sub-surface discontinuities are more pronounced for the HP case (Fig. 8) than for the CP one (Fig. 7). In Fig. 9, an illustrative 
example of the calculation of cavity numbers using the image analysing software is provided. It must be noted that the above thinning percentages correspond to the highest deformations applied during the SPF process and the other locations of the part have been deformed at much lower levels. Using the methodology described in section 2, the average number of cavities in the HP case at the highest percentage of thinning is 1500 , while for the CP samples this value is 2300 . In contrast, the overall average surface of cavities in the HP case is higher $\left(60.327 \mu \mathrm{m}^{2}\right)$ than in the $\mathrm{CP}$ one $\left(26.087 \mu \mathrm{m}^{2}\right)$. It is also worth noting that other parameters like length, width, and circular diameter of cavities are higher by a value of about $2 \mu \mathrm{m}$ in the HP processing compared to the $\mathrm{CP}$ one. This would result in larger size cavities in the case of HP samples and therefore higher susceptibility to crack formation indicating that hot preforming, contrary to the initial expectation, might not lead to the best SPF ability. The locations of these large subsurface discontinuities are very important and are favorable sites of corrosion, particularly for those which are closer to the surface.

Also, as shown in Table 2, for all percentages of thinning, the values of parameters like length, width, and circular diameter of cavities are higher in the HP case than in the $\mathrm{CP}$ one, thereby confirming the higher susceptibility of the hot preformed samples. Also, it was found that for both $\mathrm{CP}$ and HP cases, increasing the thinning percentage results in higher cavity percentage as well as other features such as length, width, and circular diameter. An exception is found for the $\mathrm{CP}$ case at the highest rate of thinning (53\%), where the percentage of surface occupied by cavities (1.45\%) is close to that for $41 \%$ of thinning $(1.47 \%)$. However, other features are totally distinct and for example, the number of cavities is about two times higher in the 53\% case compared to $41 \%$ one while the average surface is about two times lower. The higher number of cavities in $\mathrm{CP}$ samples compared to HP ones could be probably due to two competing effects: (a) occurrence of diffusion in HP samples which reduces their numbers and (b) more irregularities induced in the material structure during cold preforming which contributes to increasing their numbers.

The obtained results clearly indicate that for the same applied strain, the diffusional accommodation between cavities, where coalescence takes place, is significantly influenced by temperature. However, the influence of temperature as an external factor 
has to be taken into account along with the intrinsic parameters, such as grain size and phase proportions of harder phases, which enhance cavity nucleation.

\subsection{Grain size}

Grain size measurements were performed only on the surface zone for the SPFed parts. In the case of the base material in addition to the surface (i.e. rolling direction), observations were also made on the normal and the transverse directions. Graf Sergeant Reagent was used to reveal the grain boundaries as it can be seen on Fig. 10 where the contours of the grains in the base material are shown. This micrograph shows elongated grains in the surface zone. The average grain size was calculated to be around $36 \mu \mathrm{m}$ in the rolling direction. In the case of normal direction, Fig. 11, exploitation of the data was not readily possible from the micrograph due to the presence of cavities. An average grain size of less than $10 \mu \mathrm{m}$ was estimated in this direction. Figures 12 and 13 show typical microstructures, in the rolling direction, for cold and hot preform cases, respectively. It can be seen that the majority of the grain boundaries are decorated with precipitates. Average grain sizes of 7.95 and $8.32 \mu \mathrm{m}$ were obtained for cold and hot preform cases (Table 4), respectively.

It is well recognized that during the SPF process, grain boundary sliding plays an important role in the deformation and contribute significantly to the total strain (more than $\approx 50 \%$ ) [13]. On the other hand, it has also been reported that the stress caused by grain boundary sliding is the root cause for cavity nucleation [7]. The results obtained in the present investigation indicate that hot preform conditions lead to higher grain sizes and an increase in the nucleation of subsurface discontinuities during the SPF process should be expected. Indeed, as shown in Figs 12 and 13 and in Tables 2 and 4, while the number of cavities is higher in the case of CP samples, the average cavity surface of HP samples is higher; therefore, confirming a higher susceptibility to the formation of larger size voids and possible cracking when hot preforming route is selected. The higher undesirable surface area could be probably explained through cavity coalescence by diffusional accommodation under the applied pressure and temperature during the hot 
preforming operation [6]. The above analysis is also in agreement with those reported by Wu who observed a higher cavity nucleation under hot forming conditions [18].

Finally, it should be noted that the lower number of cavities in the HP samples (Table 2) can be related to the occurrence of sintering as reported by Verma et al. and Cleveland et al. [21, 25], who reported an adjustment of grain shape in the case of larger grain size materials (such as in HP samples) through a sintering effect. Although the number of cavities is reduced by hot preforming, their size is an important factor for initiating crack nucleation as discussed in the previous section.

\section{Conclusions}

In the present study, an analysis of the effect of pre-deformation conditions on microstructure evolution and sensitivity to the presence of cavities in Al5083-H19 SPF was undertaken. The obtained results showed that the percentage of surface occupied by cavities increases with raising the rate of thinning in both cases of preform (cold or hot). However, the number of cavities in cold preform case was higher than hot preform one, but the average cavity surface shows an inverse behaviour. Dimension of subsurface discontinuity and average grain size are higher in hot preform samples and results in higher susceptibility to crack formation which is not desirable. In contrast, cold preforming appears to lead to more consistent results in the SPF product.

\section{Acknowledgments:}

The authors acknowledge the financial support from the National Science and Engineering Research Council Canada, NSERC, in the framework of Engage Grant; Verbom Inc. for providing materials and technical support; Mr. Radu Romanica, technician at ÉTS, for his technical support in chemical solutions preparation; and finally Olympus and Hitachi Canada for access to Olympus DSX-500 Opto-digital microscope.. 


\section{References}

[1] Zamani HR, Agrawal SP, Vastava R (1987) Superplastic formed Aluminum airframe structures. Volume II - Technical details, Hawthorne: Northrop Corporation - Aircraft Division

[2] Zhang KF, Jiang SS (2014) Superplastic Forming. Comprehensive Materials Processing 5: 371-392

[3] Smith RJ, Lewi GJ, Yates D (2001) Development and application of nickel alloys in aerospace engineering. Aircraft Engineering and Aerospace Technology 73 (2): 138-147

[4] Barnes AJ, Raman H, Lowerson A, Edwards D (2013) Recent Application of Superformed 5083 Aluminum Alloy in the Aerospace Industry. Materials Science Forum 735: 361-371

[5] Chokshi AH, Mukherjee A (1989) An analysis of cavity nucleation in superplasticity. Acta Metallurgica 37 (11): 3007-3017

[6] Bae DH, Ghosh AK (2002) Cavity formation and early growth in a superplastic AlMg alloy. Acta Materialia 50: 511-523

[7] Jiang XG, Earthman JC, Mohamed FA (1994) Cavitation and cavity-induced fracture during superplastic deformation. Journal of Materials Science 29: 5499- 5514

[8] Jiang XG, Cui JZ, Ma LX (1993) The influence of the rolling direction on the mechanical behavior and cavity formation during superplastic deformation of 7075 A1 alloy. Acta Metall. Mater. 41 (9): 2721-2727

[9] Chokshi AH, Langdon TG (1990) The nucleation and growth of cavities in a superplastic quasi-single phase copper alloy. Acta Metall. Mater. 38 (5): 867-877

[10] Jiang XG (1992) A study of cavity nucleation during superplastic deformation of high strength aluminum alloy 7475. Mater. Sci. Eng. A157: 37-41

[11] Chokshi AH, Langdon TG (1989) The influence of rolling direction on the mechanical behavior and formation of cavity stringers in the superplastic $\mathrm{Zn}-22 \% \mathrm{Al}$ alloy. Acta Metallurgica 37 (2): 715-723

[12] Chan KS, Page RA, Lankford J (1986) Cavity nucleation at grain boundary ledges. Acta Metallurgica 34 (12): 2361-2370

[13] Pilling J, Ridley N (1988) Effect of Hydrostatic Pressure on Cavitation in Superplastic Alloys. Res Mechanica 23: 31-63 
[14] Stowell MJ (1983) Failure of superplastic alloys. Metal Science 17 (1): 1-11

[15] Kashyap BP, Mukherjee AK (1986) Cavitation Behaviour During High Temperature Deformation of Micrograined Superplastic Materials. Res. Mechanica 17: 293-355

[16] Chokshi AH (2005) Cavity nucleation and growth in superplasticity. Mater.

Sci. Eng. A 410-411: 95-99

[17] Guo ZX , Ridley N (1990) Effect of stress state on cavitation and hole growth in superplastic AA 7475 aluminium alloy. Materials Science and Technology 6 (6): 516-519

[18] Wu HY (2000) Influence of deformation variables on cavitation of a superplastic 5083 Aluminum alloy. Materials and Manufacturing Processes 15 (2): 231-245

[19] Chan KC, Chow KK (2002) The stress state dependence of cavitation in commercial superplastic Al5083 alloy. Materials Letters 56: 38-42

[20] Chow KK, Chan KC (2001) The cavitation behavior of a coarse-grained Al5052 alloy under hot uniaxial and equi-biaxial tension. Materials Letters 49: 189-196

[21] Verma R, Friedman PA, Ghosh AK, Kim S, Kim C (1996) Characterization of Superplastic Deformation Behavior of a Fine Grain 5083 Al Alloy Sheet. Metallurgical and Materials Transactions A (27A): 1889-1898

[22] Bae DH, Ghosh AK (2002) Observations related to healing of interface damage and cavity nucleation during superplastic flow. Mater. Sci. Eng. A 322: 233-240

[23] Nahamin Pardazan (2014) Asia, 〈http://en.metsofts.ir/>, Iran

[24] Hauffe W (1991) Production of microstructures by ion beam sputtering 6; Sputtering by Particle Bombardment III. Springer-Verlag Berlin 64: 305-338

[25] Cleveland RM, Ghosh AK, Bradley JR (2003) Comparison of superplastic behavior in two 5083 aluminum alloys. Mater. Sci. Eng. A 351: 228-236

\section{Figures captions}

Fig.1 Geometries of the preforms (a)and of the final pieces (b)

Fig.2 SEM image in normal direction for the base material 
Fig.3 Cavity length range distribution

Fig.4 SEM image for cold preform case (rolling direction)

Fig.5 SEM image for hot preform case (rolling direction)

Fig.6 SEM images showing precipitates: (a) with SE mode

Fig.6 SEM images showing precipitates: (b) with BSE mode

Fig.6 SEM images: (c) showing Mn distribution

Fig.7 Optical micrographs for CP sample (rolling direction), zone 1

Fig.7 Optical micrographs for CP sample (rolling direction), zone 2

Fig.7 Optical micrographs for CP sample (rolling direction), zone 3

Fig.8 Optical micrographs for HP sample (rolling direction), zone 1

Fig.8 Optical micrographs for HP sample (rolling direction), zone 2

Fig.8 Optical micrographs for HP sample (rolling direction), zone 3

Fig.9 Illustrative optical micrograph image used in MIP software

Fig.10 Optical micrograph of the base material (rolling direction), showing grain boundaries

Fig.11 Optical micrograph of the base material (normal section)

Fig.12 SEM images of grain for CP case (rolling direction), zone 1

Fig.12 SEM images of grain for CP case (rolling direction), zone 2

Fig.12 SEM images of grain for CP case (rolling direction), zone 3

Fig.13 SEM images of grain for HP case (rolling direction), zone 1

Fig.13 SEM images of grain for HP case (rolling direction), zone 2 
Fig.13 SEM images of grain for HP case (rolling direction), zone 3

\section{Tables}

Table 1 Chemical composition (wt.\%) of the studied material

\begin{tabular}{ccccccccc}
\hline & Si & Fe & Cu & Mn & Mg & Cr & Zr & Ti \\
Min. & & & & 0.4 & 4 & 0.05 & & \\
Max. & 0.4 & 0.4 & 0.1 & 1 & 4.9 & 0.25 & 0.25 & 0.15 \\
\hline
\end{tabular}

Table 2 Characteristics of CP and HP parts (rolling direction)

\begin{tabular}{|c|c|c|c|c|c|c|c|c|c|}
\hline & Locations & $\begin{array}{l}\text { Thickness } \\
(\mathrm{mm})\end{array}$ & $\begin{array}{c}\text { Thinning } \\
(\%)\end{array}$ & $\begin{array}{l}\text { Number of } \\
\text { cavities per } \\
\text { unit surface }\end{array}$ & $\begin{array}{c}\text { Average } \\
\text { cavity } \\
\text { surface } \\
\left(\mu \mathrm{m}^{2}\right)\end{array}$ & $\begin{array}{c}\text { Surface } \\
\text { occupied by } \\
\text { cavities (\%) }\end{array}$ & $\begin{array}{c}\text { Average } \\
\text { cavity } \\
\text { length } \\
(\mu \mathrm{m})\end{array}$ & $\begin{array}{c}\text { Average } \\
\text { cavity } \\
\text { width } \\
(\mu \mathrm{m})\end{array}$ & $\begin{array}{c}\text { Average } \\
\text { cavity } \\
\text { circular } \\
\text { diameter } \\
(\mu \mathrm{m}) \\
\end{array}$ \\
\hline \multirow{4}{*}{$\mathrm{CP}$} & $\mathrm{a}$ & 1.076 & 32 & 668 & 35.99 & 0.58 & 5.34 & 3.43 & 6.16 \\
\hline & $\mathrm{b}$ & 1.008 & 37 & 974 & 47.89 & 1.13 & 6.52 & 4.1 & 6.86 \\
\hline & $\mathrm{c}$ & 0.935 & 41 & 1133 & 53.64 & 1.47 & 6.88 & 4.42 & 7.2 \\
\hline & $\mathrm{d}$ & 0.74 & 53 & 2300 & 26.087 & 1.45 & 5.083 & 2.52 & 5.188 \\
\hline \multirow{4}{*}{$\mathrm{HP}$} & $\mathrm{a}$ & 1.14 & 28 & 804 & 40.71 & 0.79 & 5.62 & 3.26 & 6.39 \\
\hline & $\mathrm{b}$ & 1.084 & 32 & 862 & 49.003 & 1.02 & 6.554 & 4.29 & 7.06 \\
\hline & $\mathrm{c}$ & 0.875 & 45 & 1081 & 52.52 & 1.38 & 7.05 & 4.53 & 7.3 \\
\hline & $\mathrm{d}$ & 0.71 & 55 & 1500 & 60.327 & 2.2 & 7.640 & 4.497 & 7.274 \\
\hline
\end{tabular}

Table 3 EDS analysis of precipitates (wt.\%)

\begin{tabular}{cccccc}
\hline Spectrum & $\boldsymbol{O}$ & $\boldsymbol{M g}$ & $\boldsymbol{A l}$ & $\boldsymbol{C r}$ & $\boldsymbol{M n}$ \\
\hline $\boldsymbol{1}$ & 0.52 & 5.16 & 91.71 & - & - \\
$\mathbf{2}$ & - & 5.23 & 91.80 & - & 0.47 \\
$\mathbf{3}$ & - & 5.18 & 91.22 & - & 0.97 \\
$\mathbf{4}$ & - & 5.04 & 90.31 & 0.36 & 1.79 \\
$\mathbf{5}$ & - & 5.17 & 91.36 & - & 0.84 \\
\hline
\end{tabular}


Table 4 Average grain size measurement for $\mathrm{CP}$ and HP cases (rolling direction)

\begin{tabular}{ccc}
\hline & Cold preform & Hot preform \\
\cline { 2 - 3 } Zone 1 & 8.419 & 8.412 \\
Zone 2 & 7.783 & 8.066 \\
Zone 3 & 7.652 & 8.5 \\
\hline Average $(\boldsymbol{\mu m})$ & $\mathbf{7 . 9 5}$ & $\mathbf{8 . 3 2}$ \\
\hline
\end{tabular}
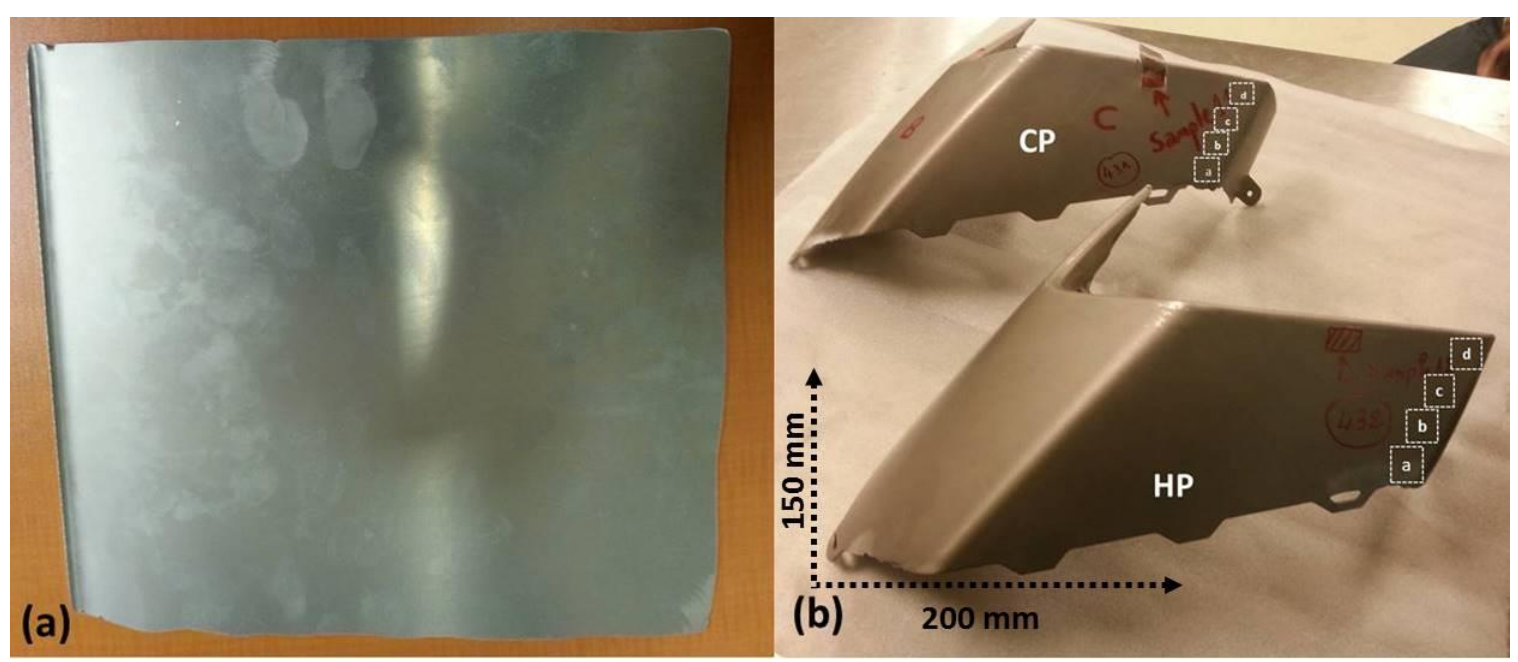

Figure 1. Dimension of the preforms (a)and the final pieces geometry (b) 


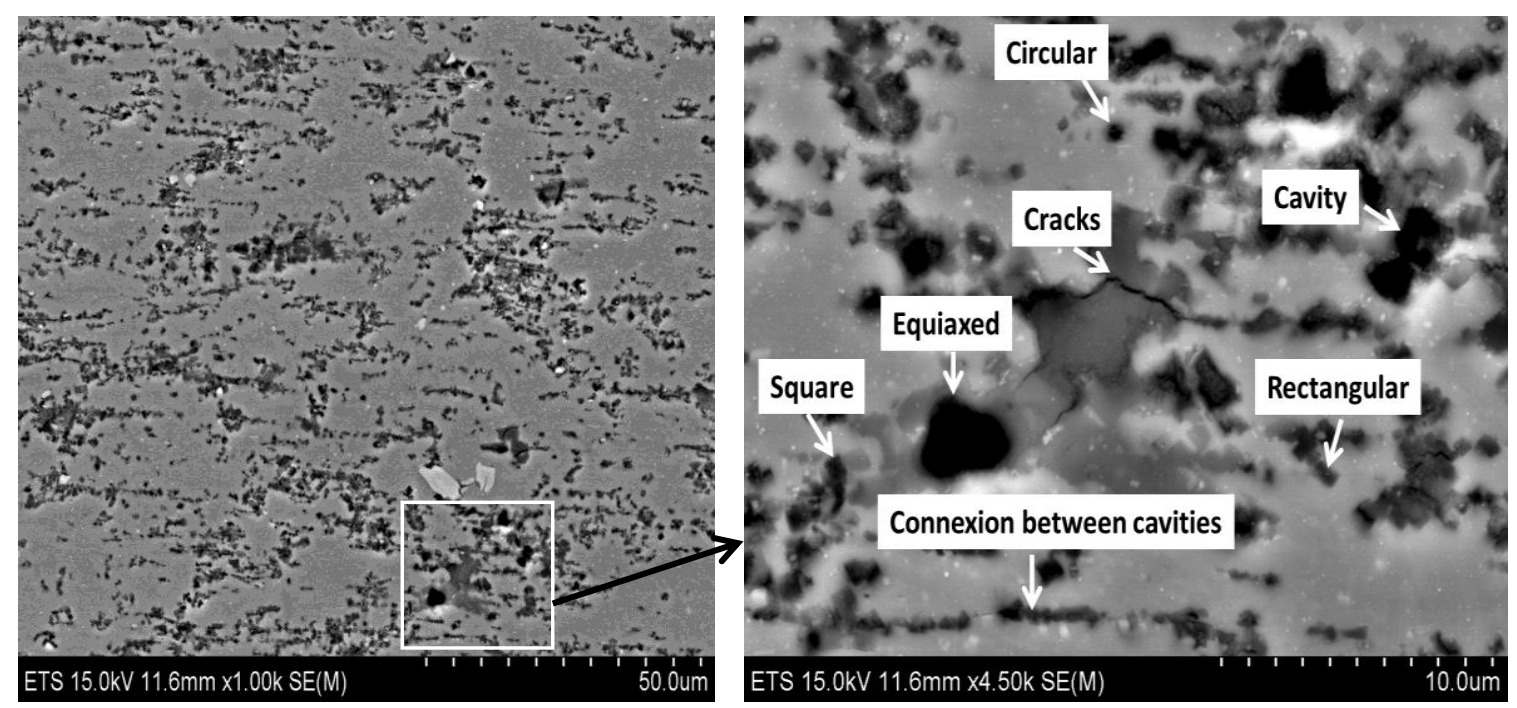

Figure 2. SEM image in normal direction for the base material

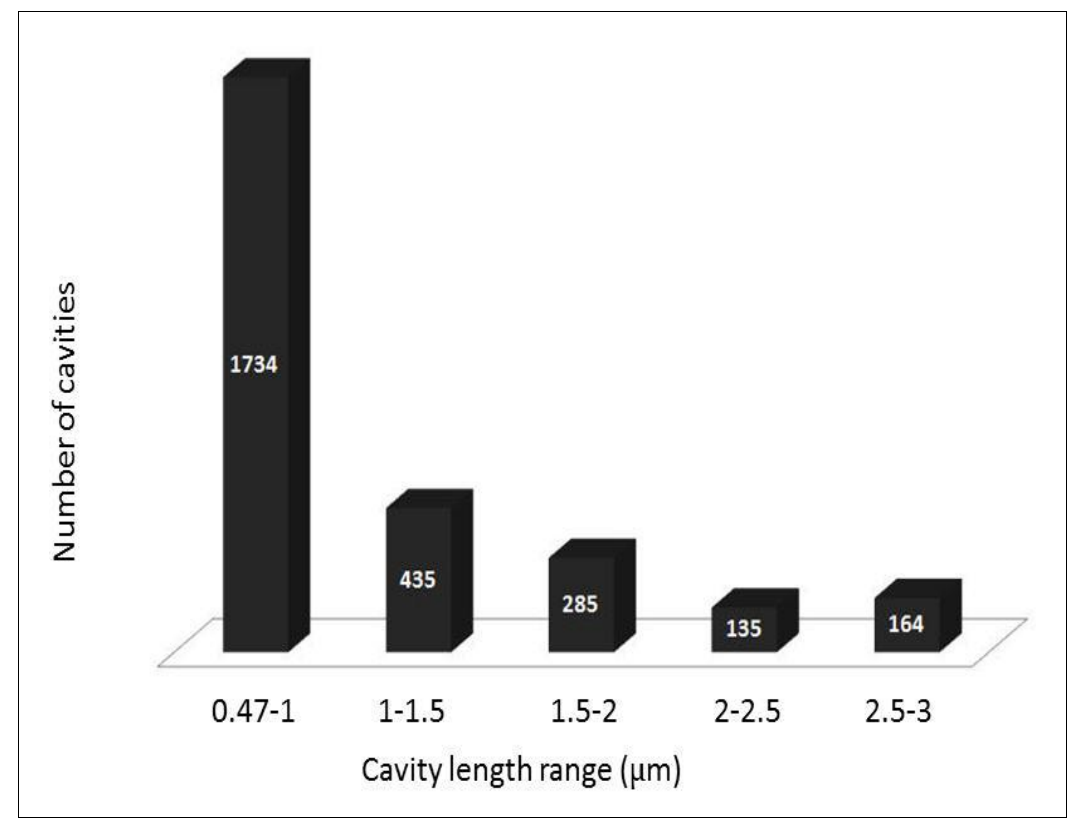

Figure 3. Cavity length range distribution 


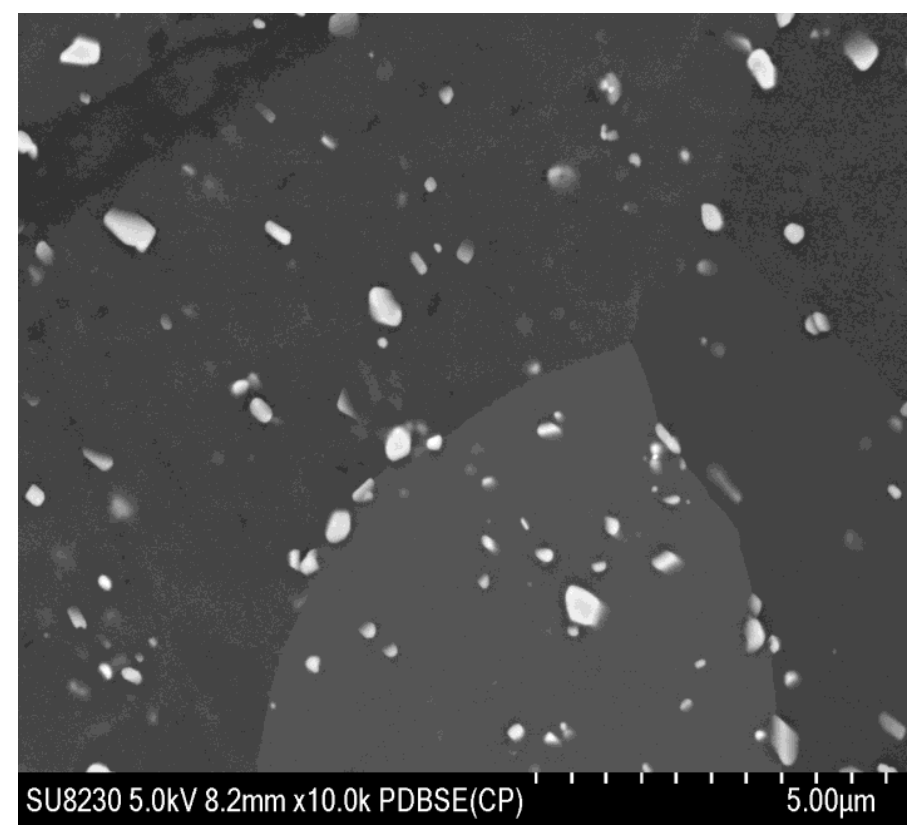

Figure 4. SEM image for cold preform case (rolling direction)

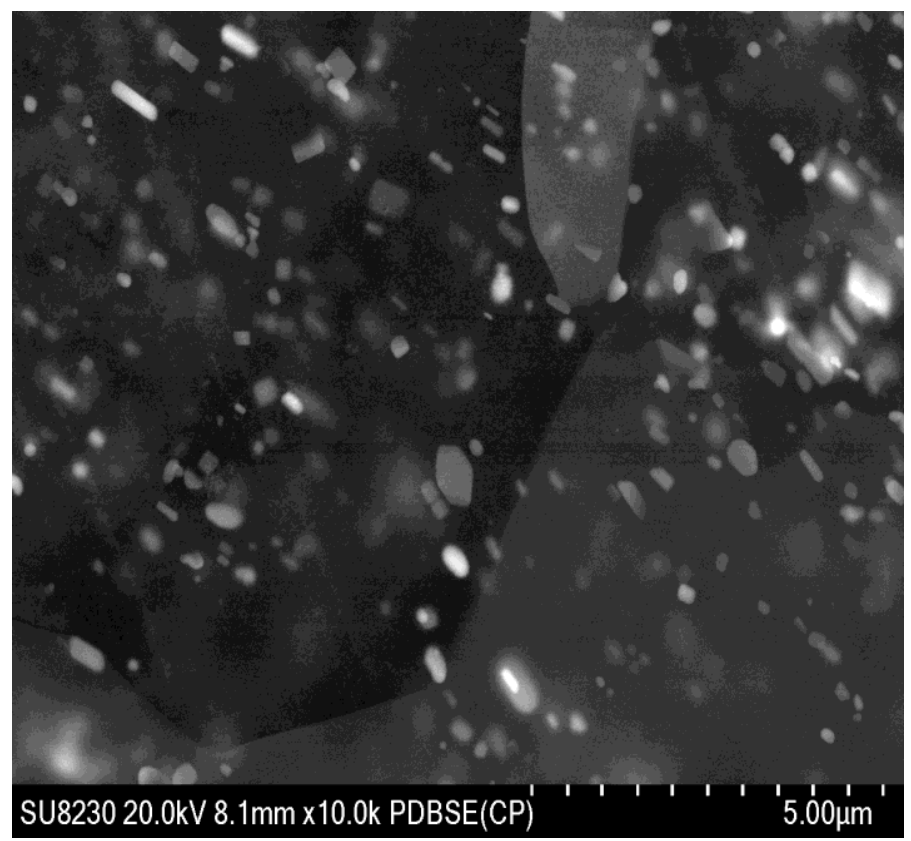

Figure 5. SEM image for hot preform case (rolling direction) 


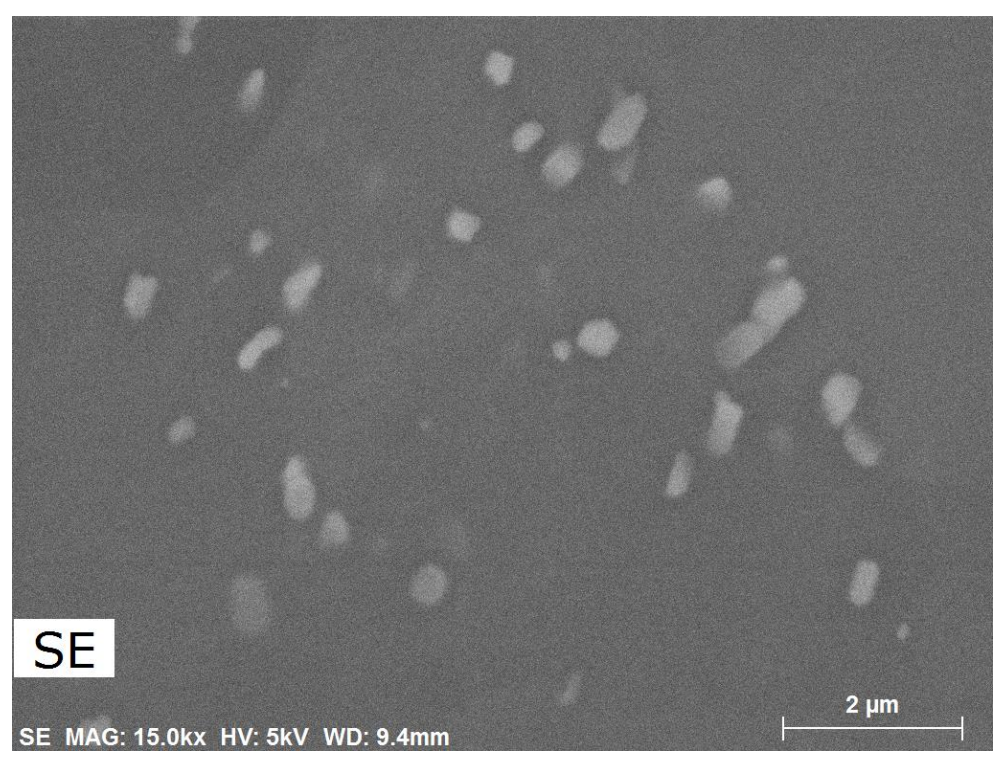

Figure 6. SEM images showing precipitates. (a) with SE mode

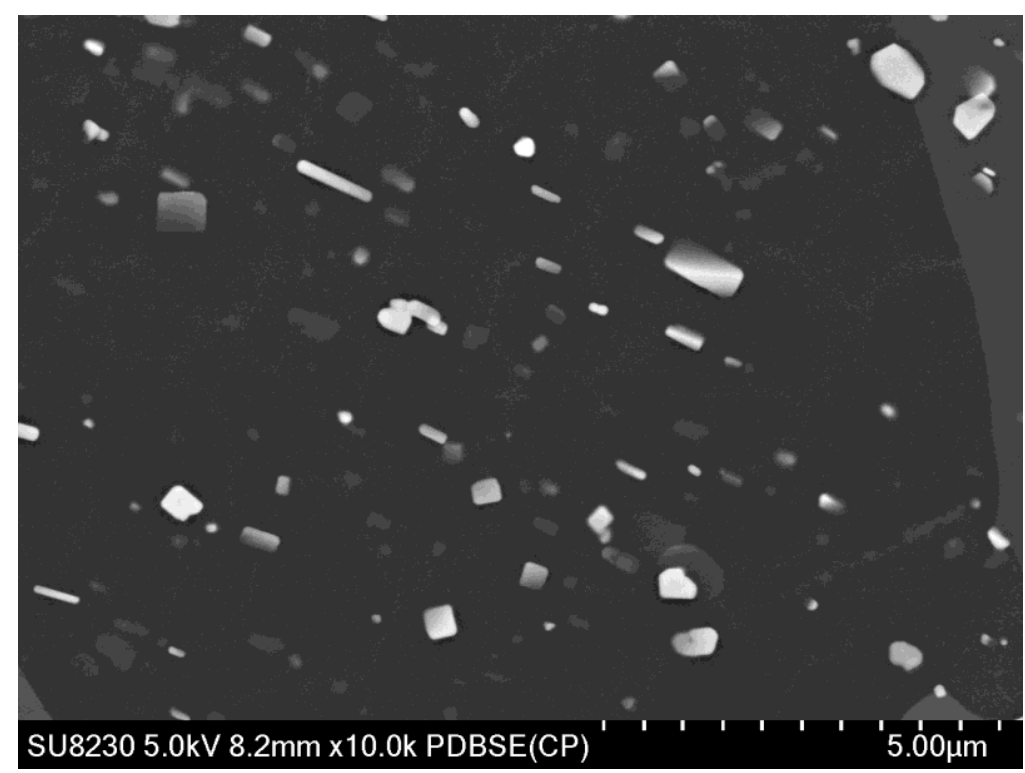

Figure 6. SEM images showing precipitates. (b) with BSE mode 


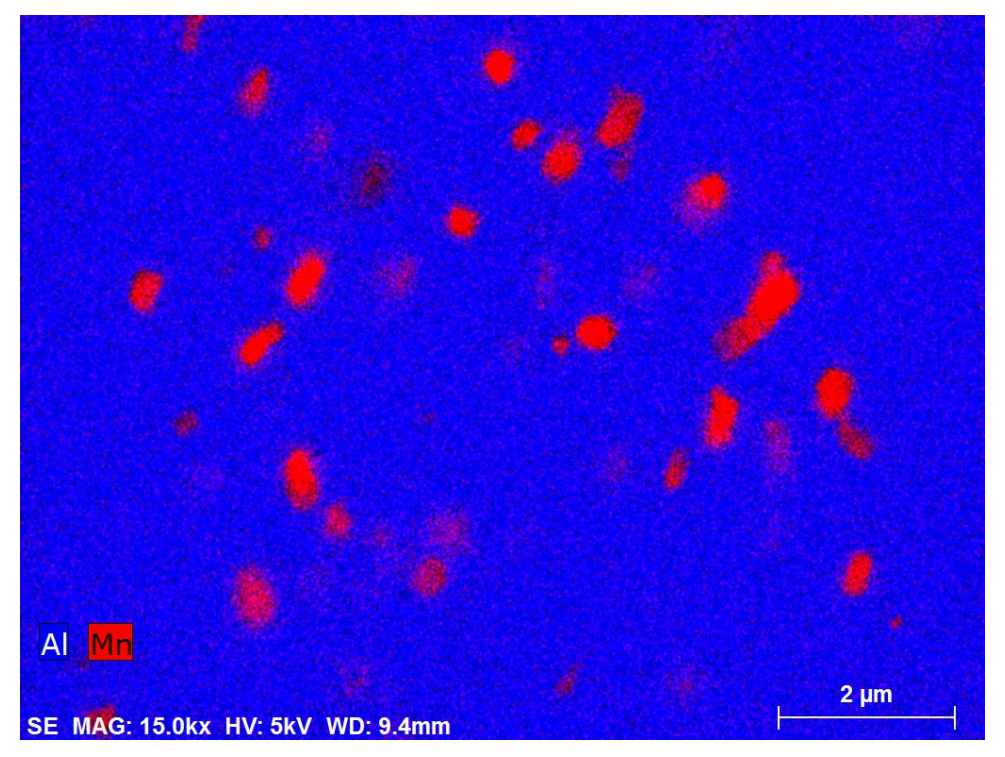

Figure 6. SEM images. (c) showing Mn distribution

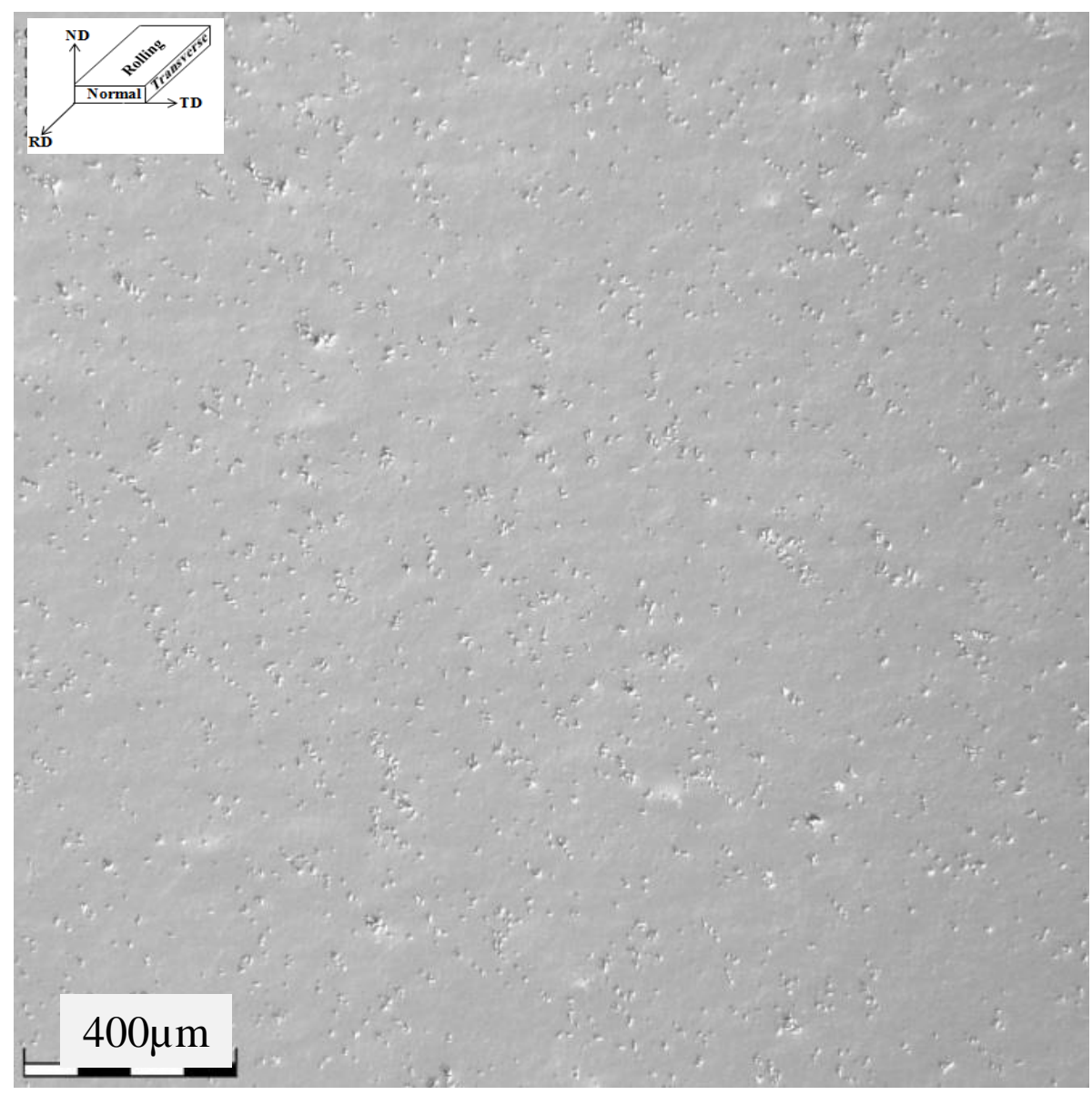

Figure 7. Optical micrographs for CP sample (rolling direction), zone 1 


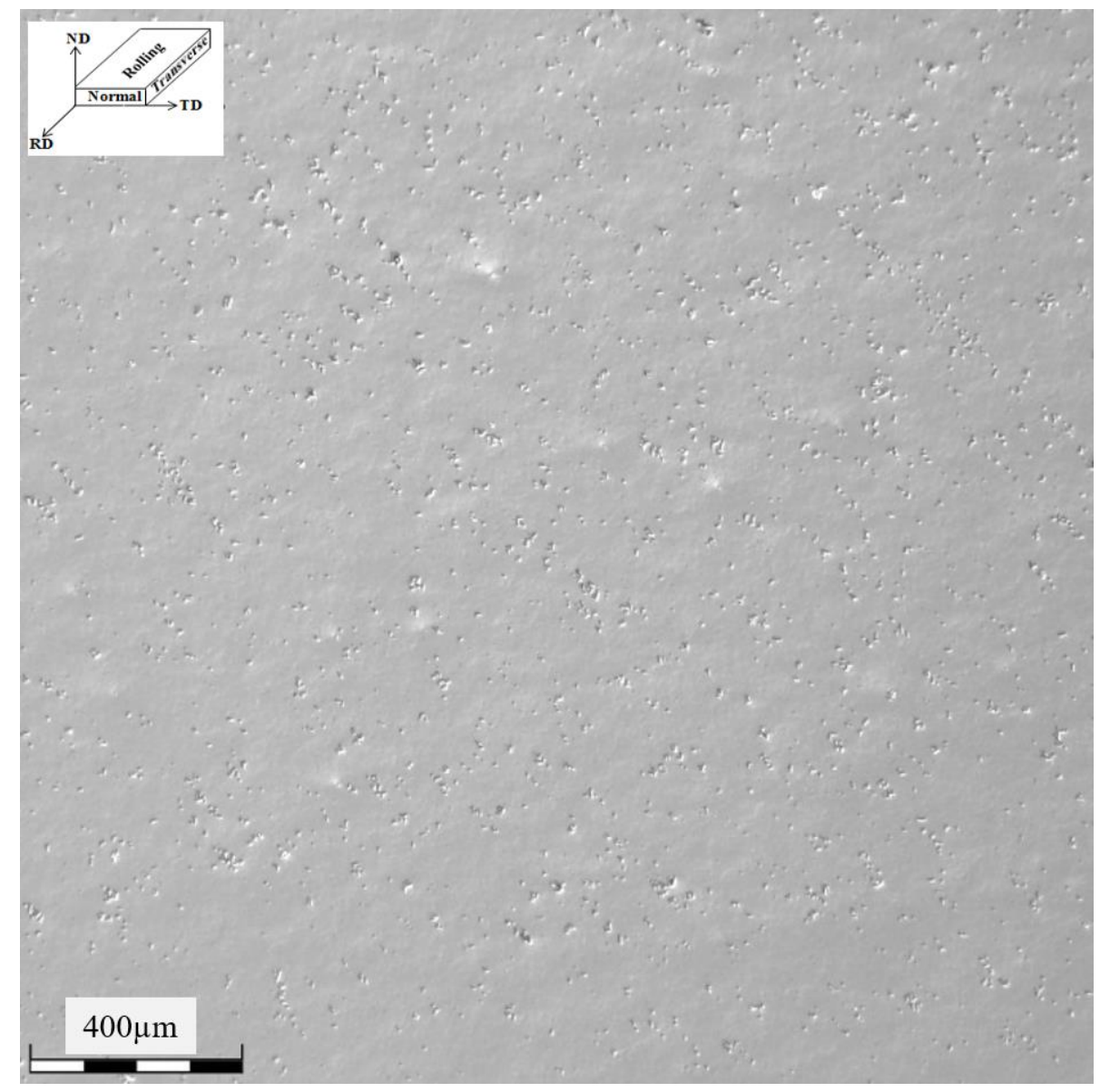

Figure 7. Optical micrographs for CP sample (rolling direction), zone 2 


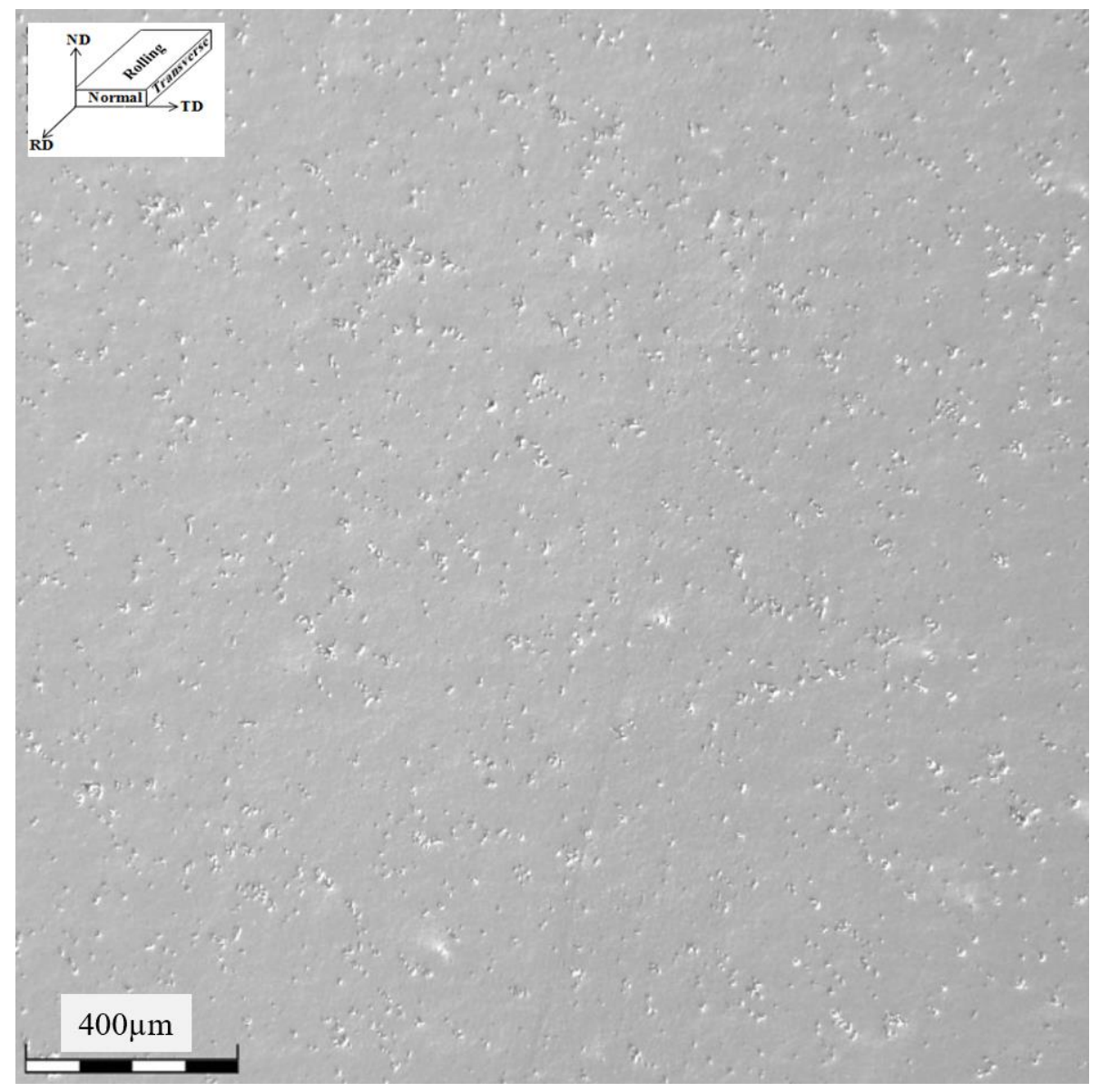

Figure 7. Optical micrographs for CP sample (rolling direction), zone 3 


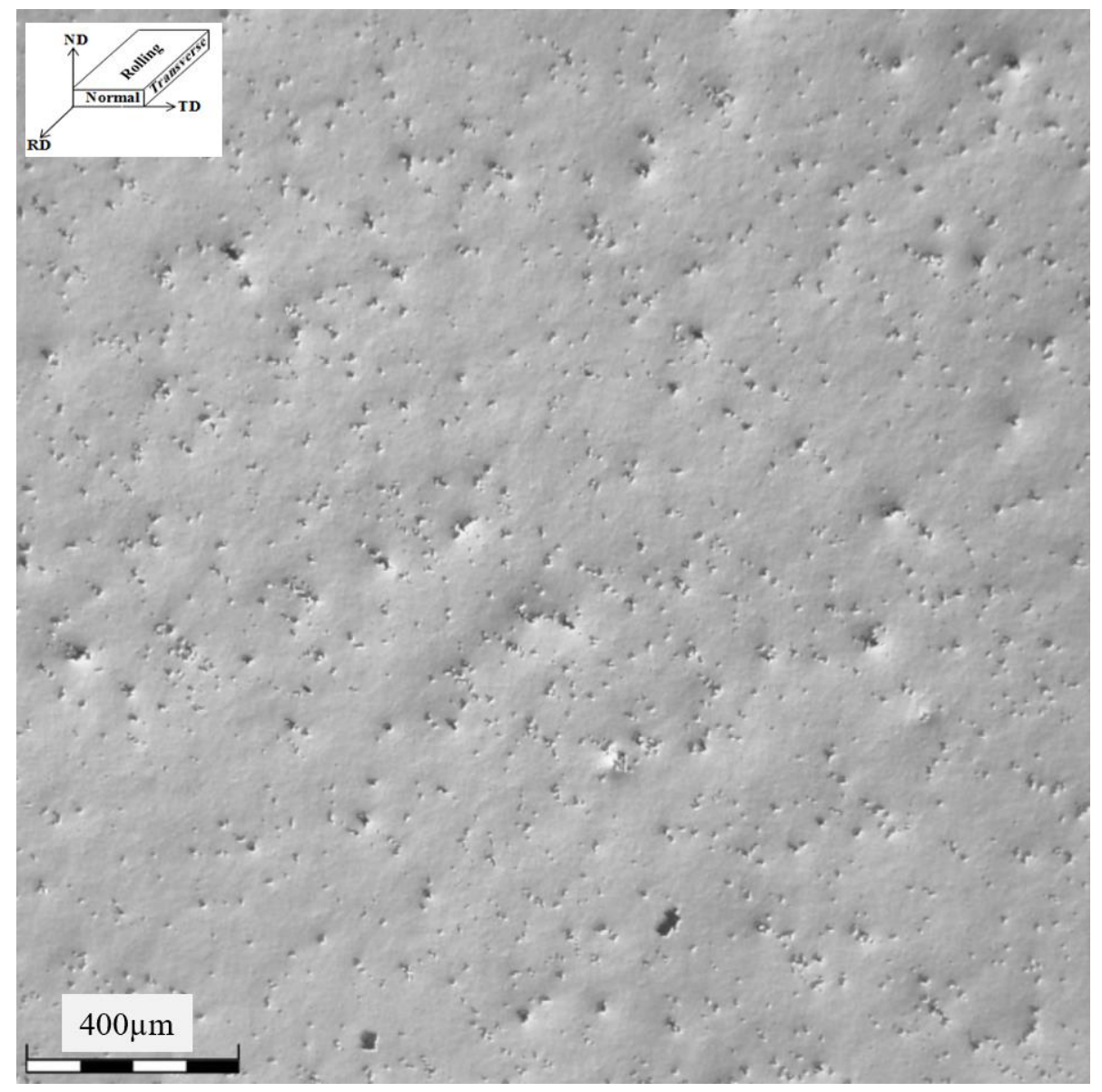

Figure 8. Optical micrographs for HP sample (rolling direction), zone 1 


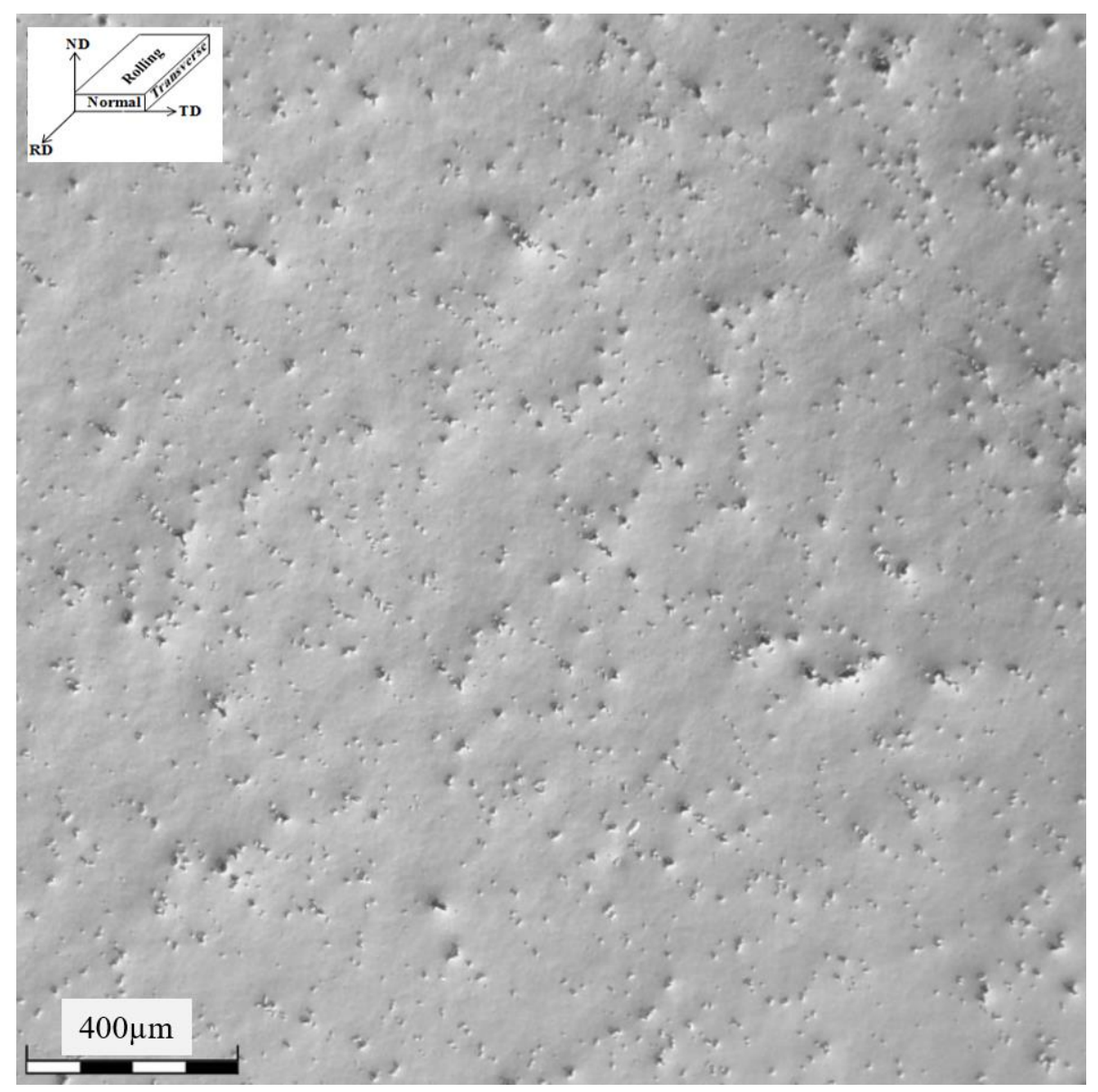

Figure 8. Optical micrographs for HP sample (rolling direction), zone 2 


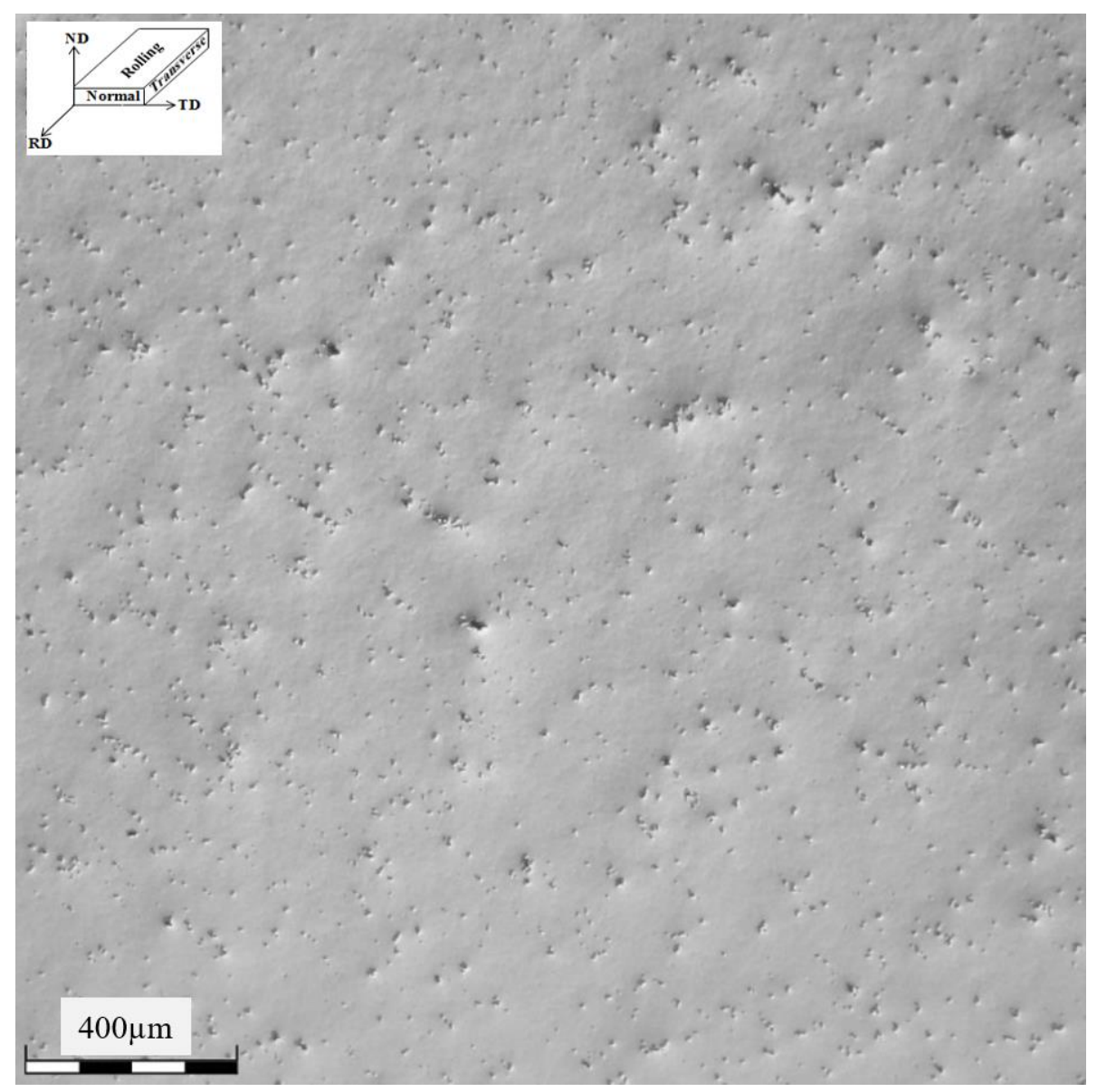

Figure 8. Optical micrographs for HP sample (rolling direction), zone 3 


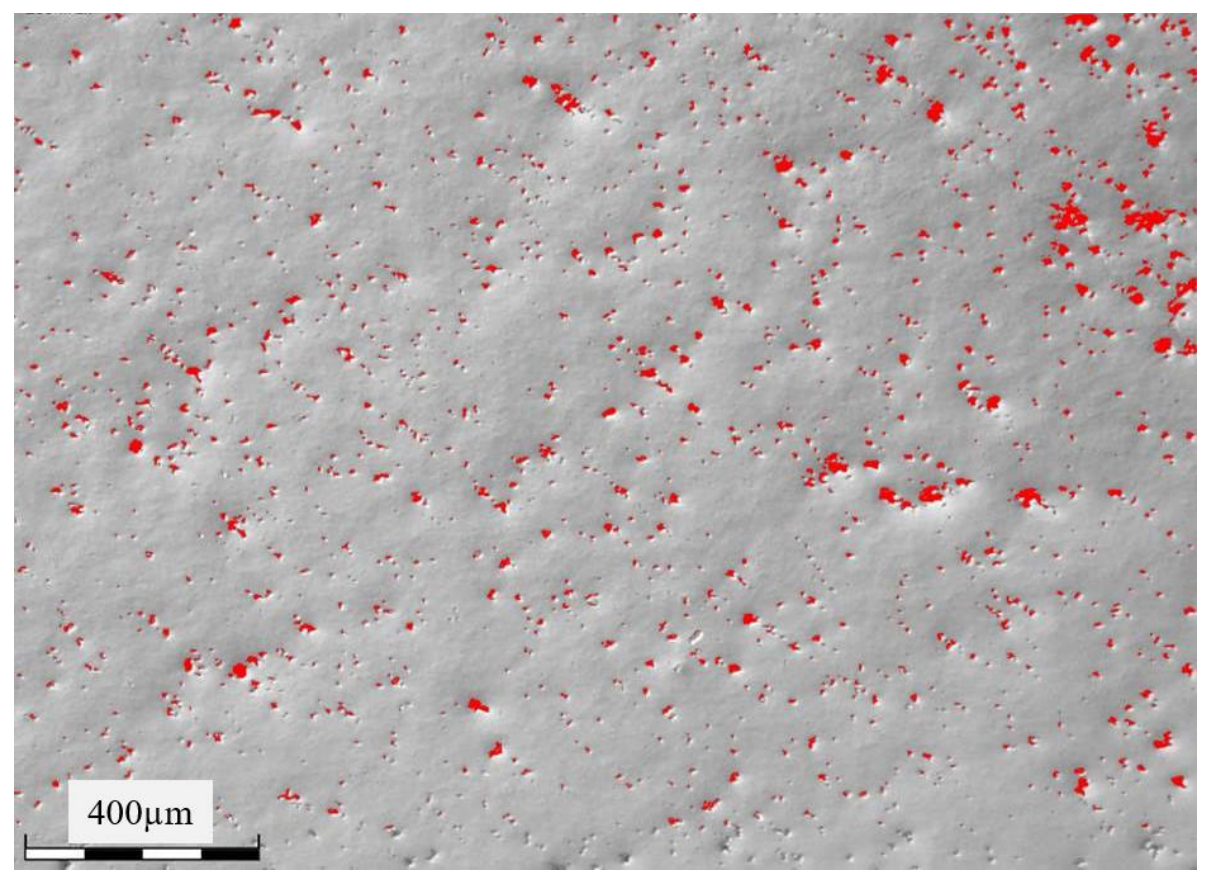

Figure 9. Illustrative optical micrograph image used in MIP software

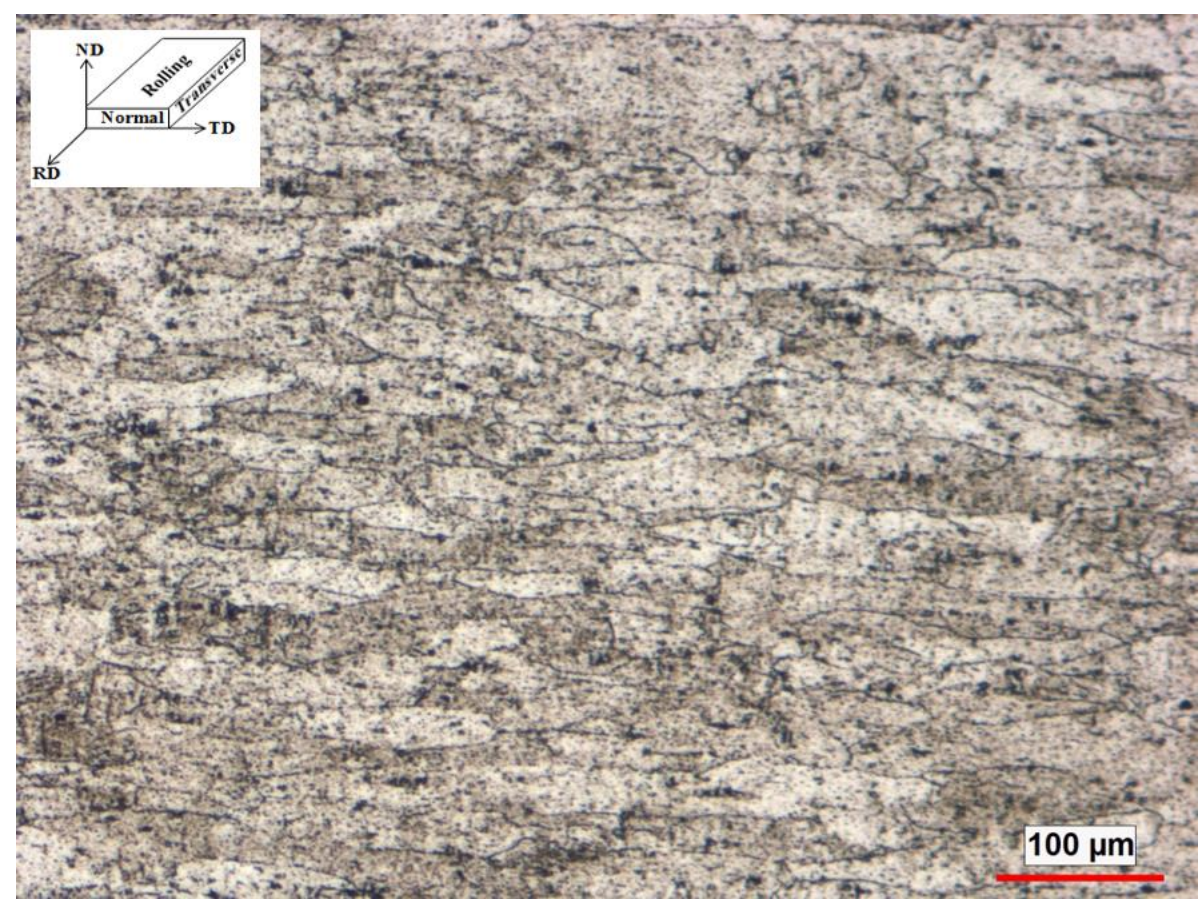

Figure 10. Optical micrograph of the base material (rolling direction), showing

grain boundaries 


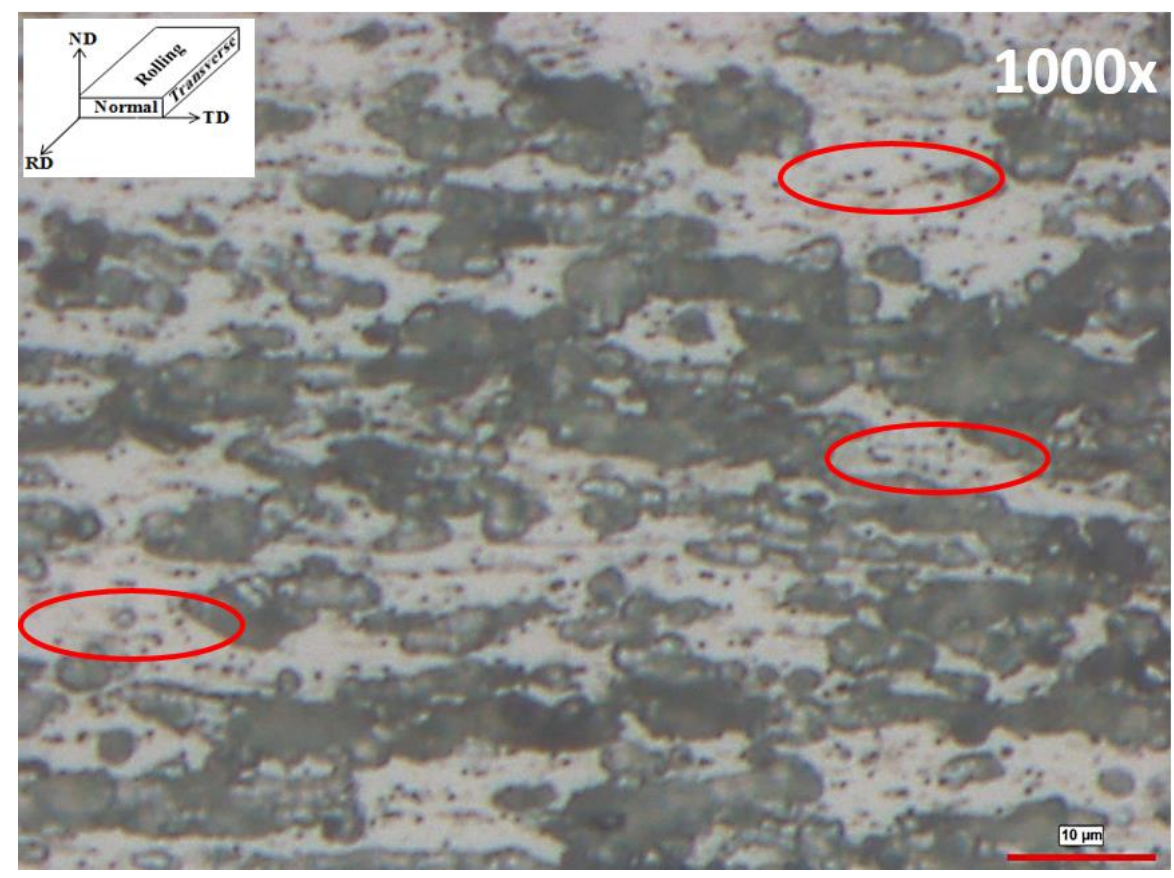

Figure 11. Optical micrograph of the base material (normal section)

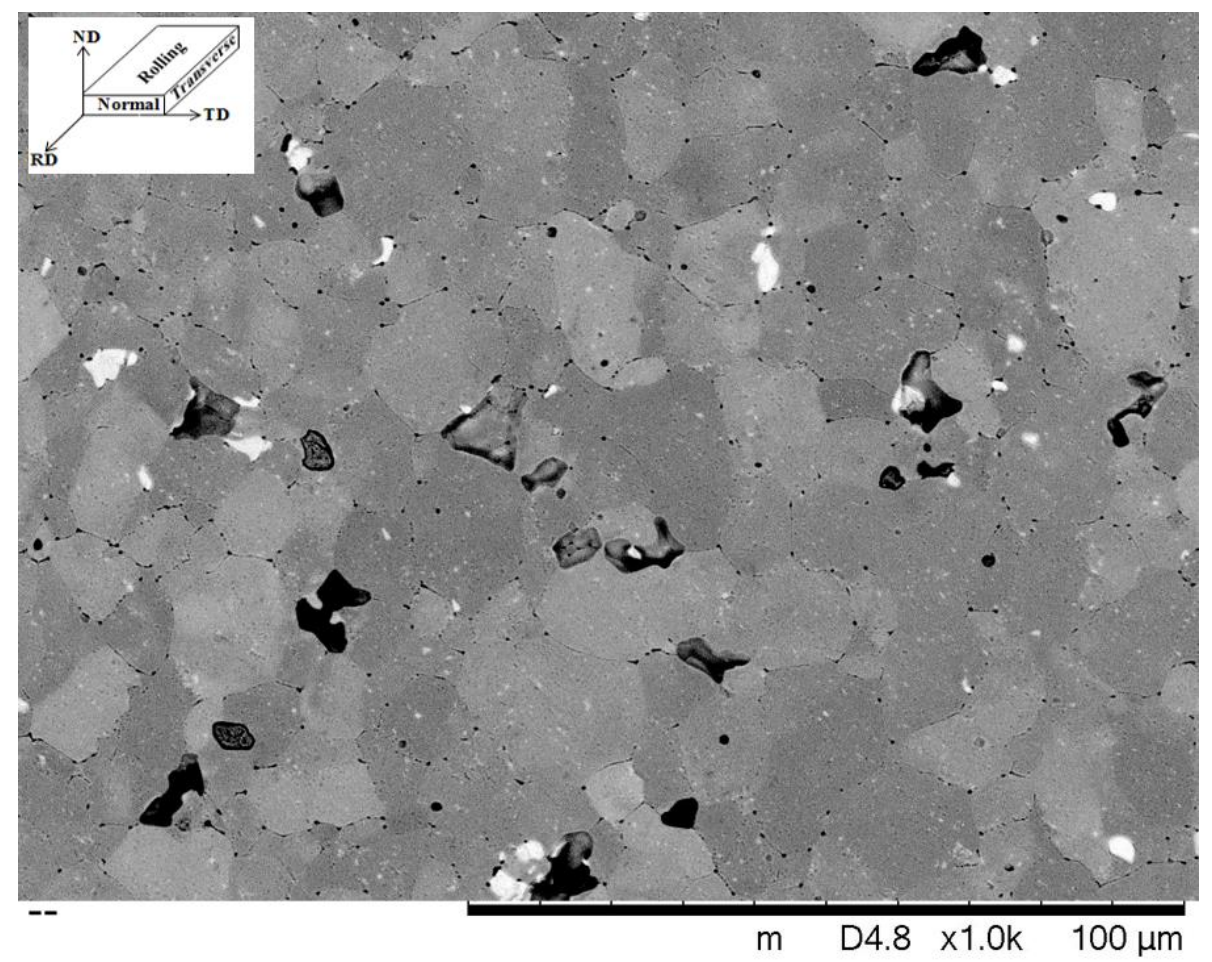

Figure 12. SEM images of grain for CP case (rolling direction), zone 1 


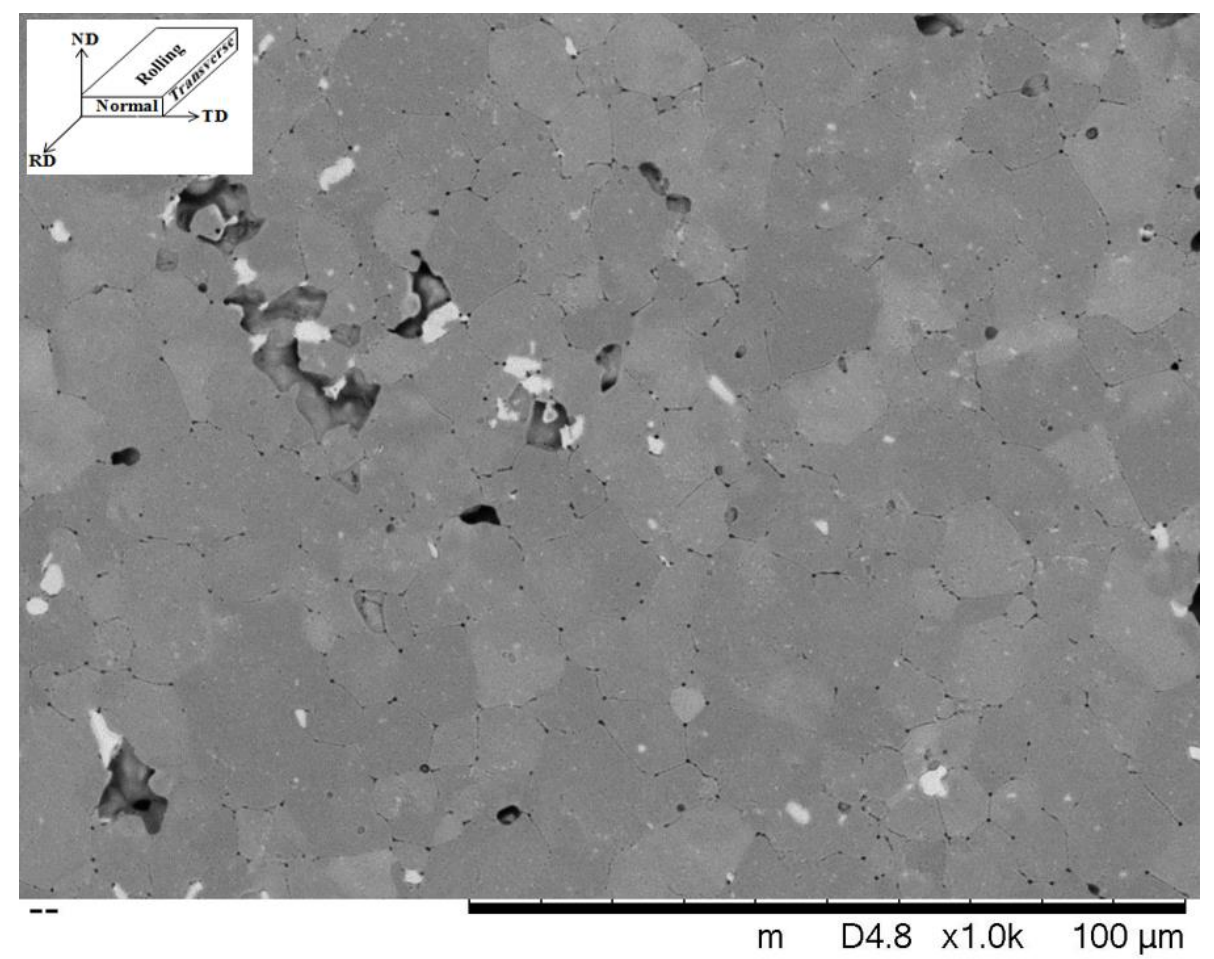

Figure 12. SEM images of grain for CP case (rolling direction), zone 2

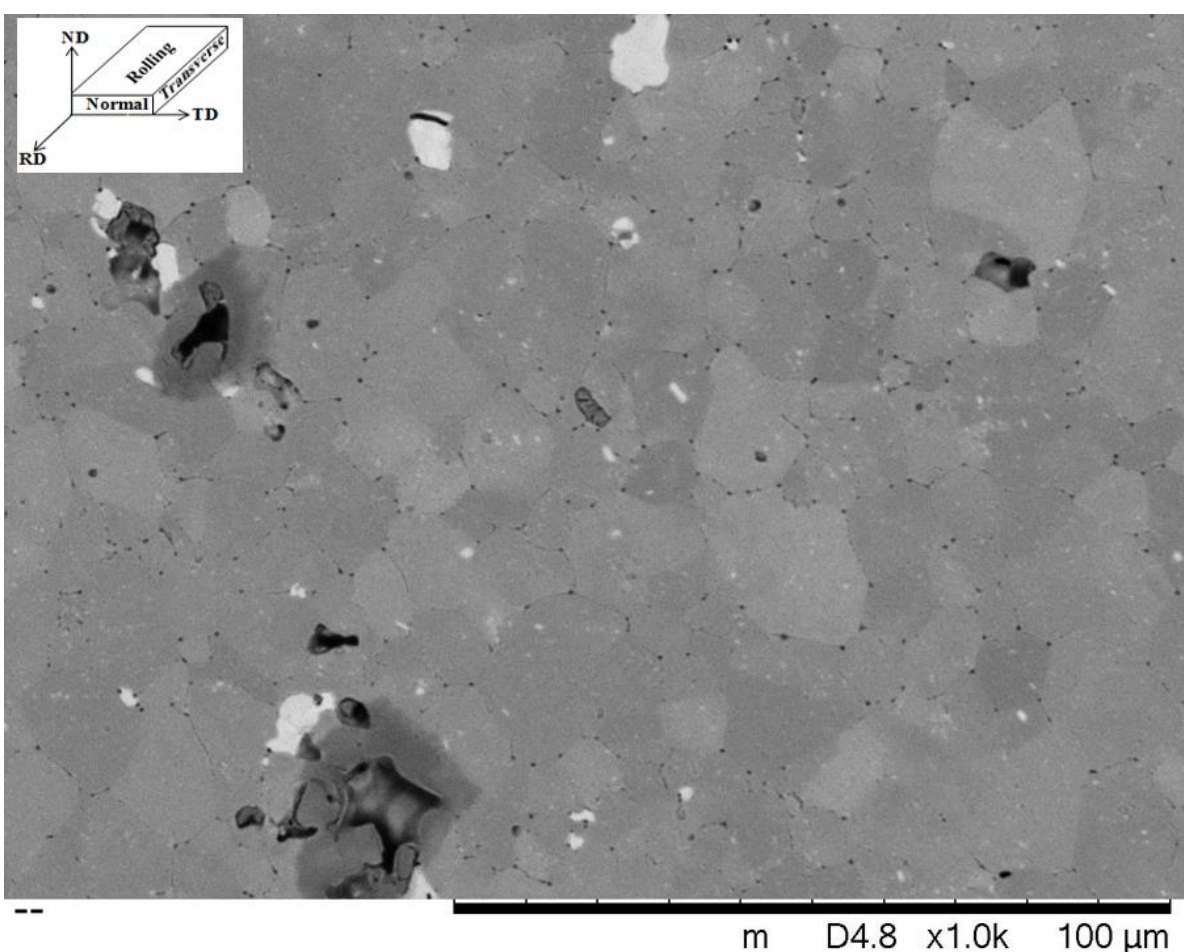

Figure 12. SEM images of grain for CP case (rolling direction), zone 3 


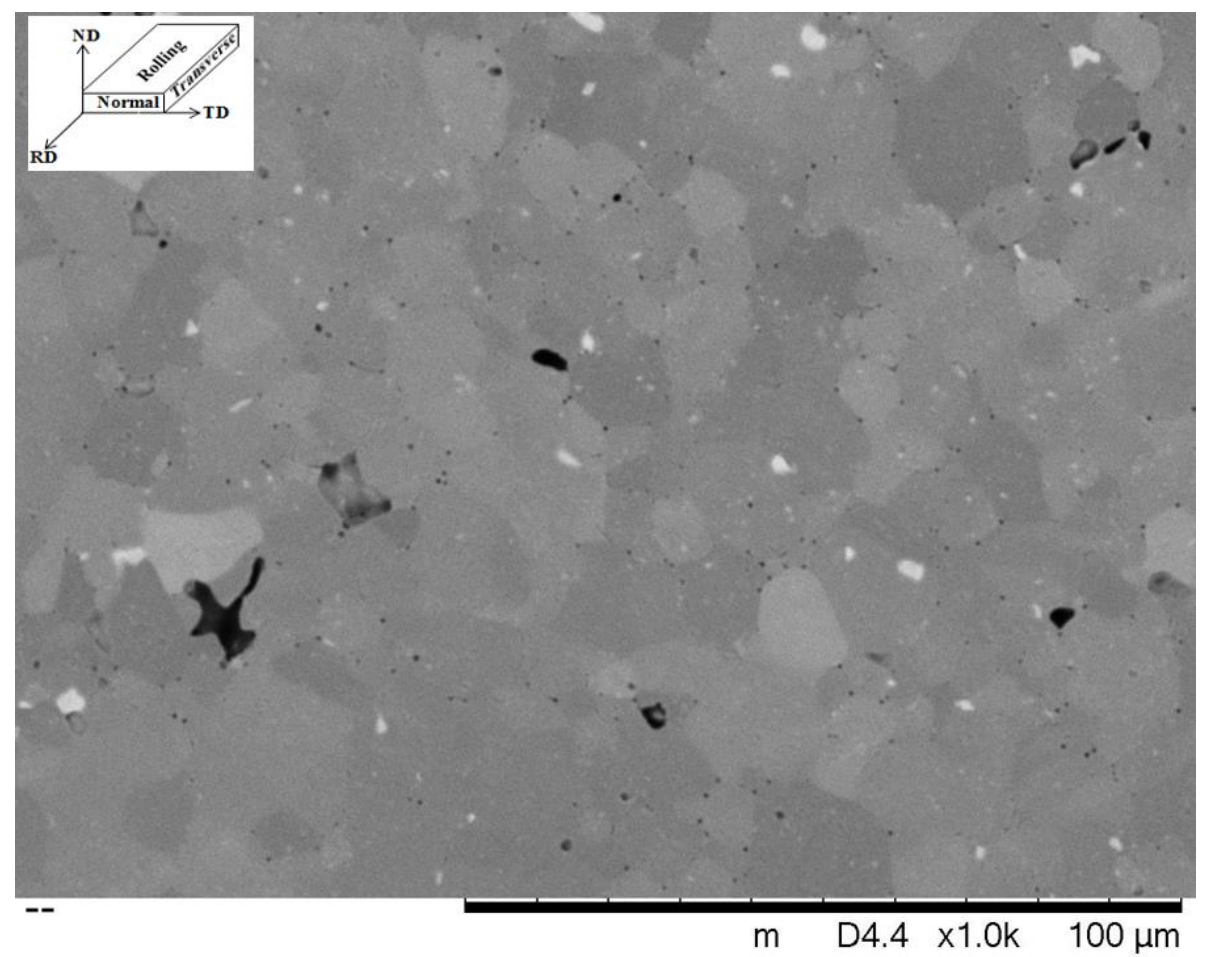

Figure 13. SEM images of grain for HP case (rolling direction), zone 1

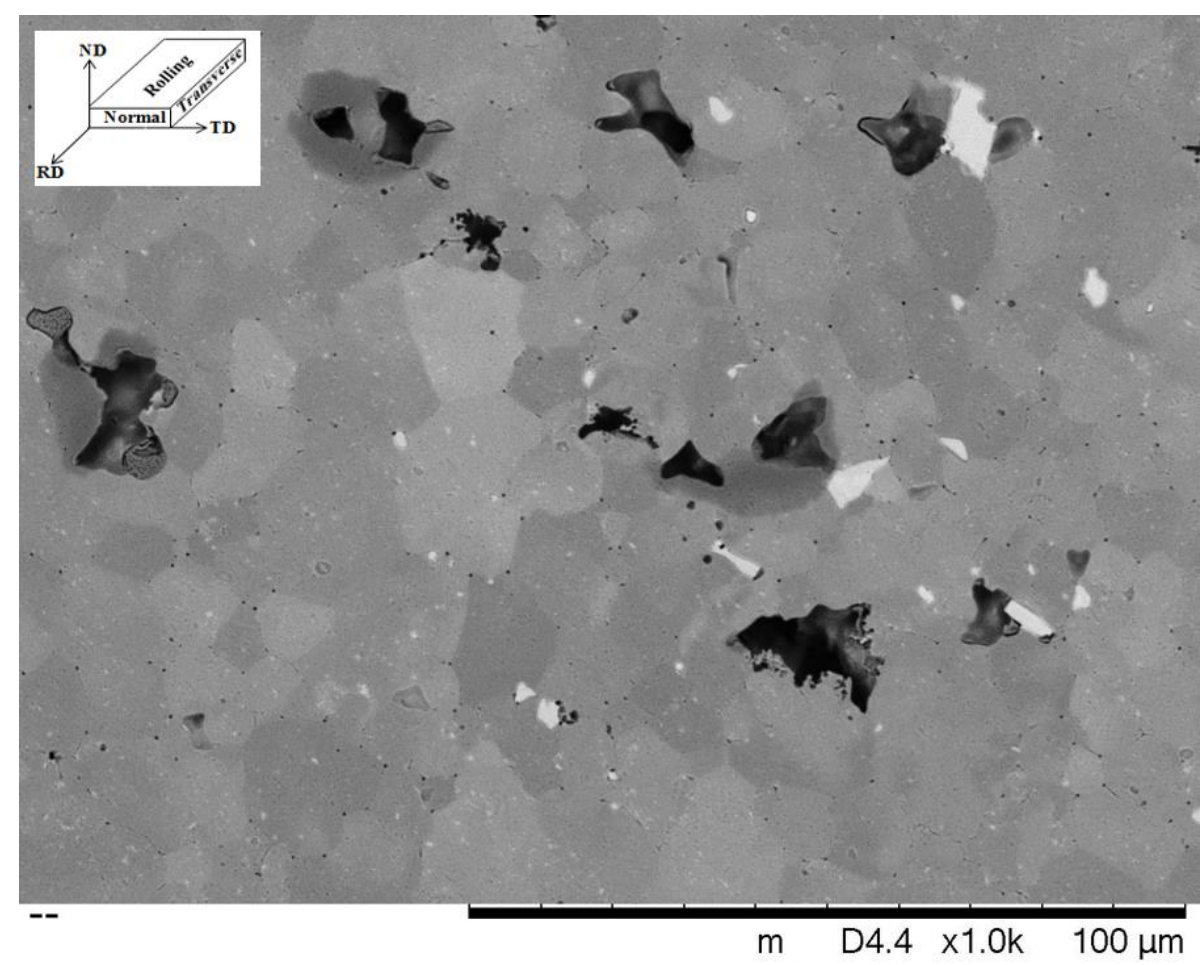

Figure 13. SEM images of grain for HP case (rolling direction), zone 2 


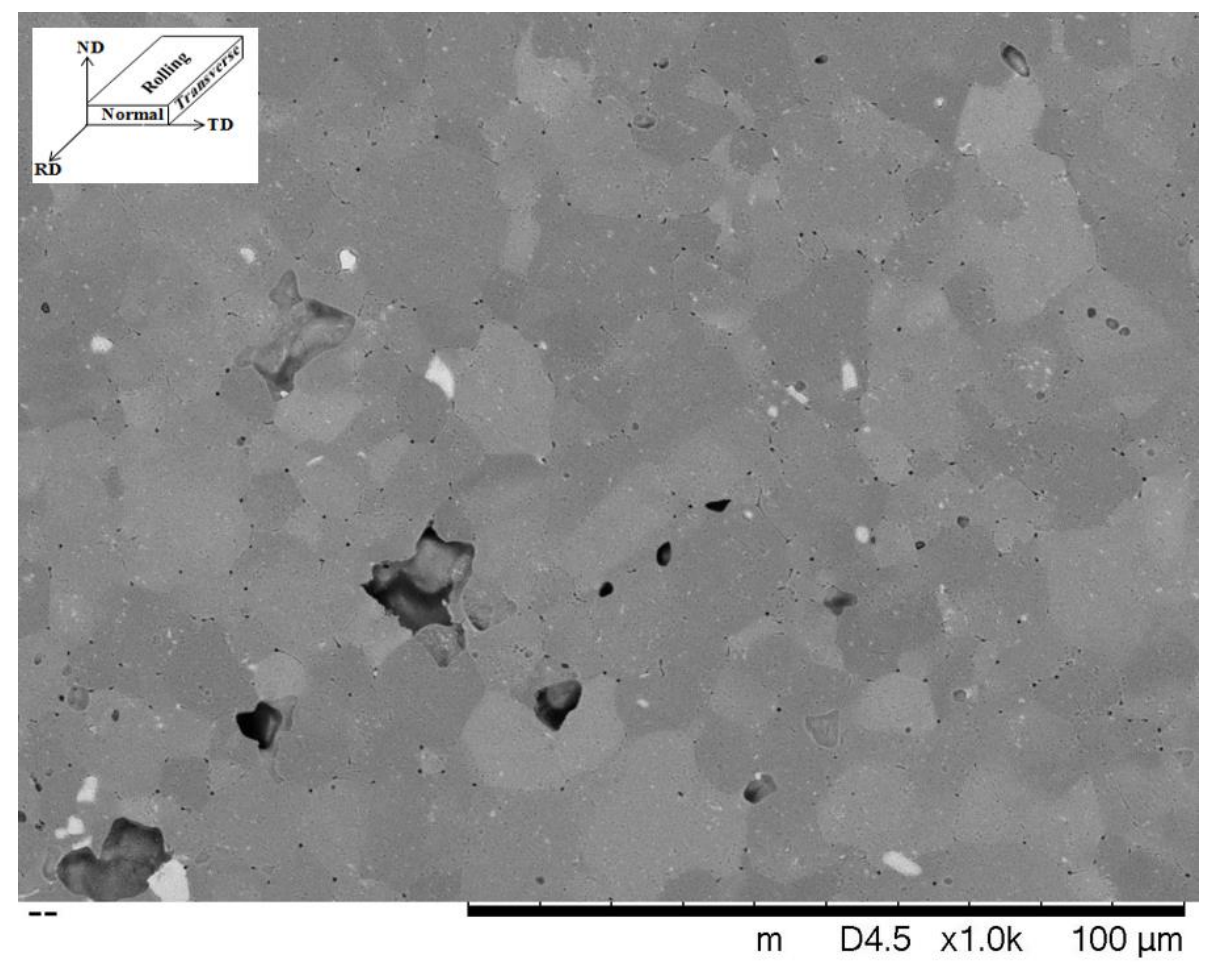

Figure 13. SEM images of grain for HP case (rolling direction), zone 3 